\title{
VARIASI GROUND PLANE ANTENA COLLINEAR PADA PEMANCAR TELIVISI ANALOG DENGAN FREKUENSI UHF $442 \mathrm{MHz}$
}

\author{
Eddy Endrayana, Dinar H.S Wahyuni, Nachrowie, Irfan Mujahidin \\ Jurusan Teknik Elektro UNMER Malang \\ e-mail: eddyendrayana@gmail.com
}

\begin{abstract}
Abstrak
Antena merupakan piranti transmisi yang penting dalam system penerima sinyal televisi, sebab tidak dimungkinkan lagi jika kabel tembaga dipakai sebagai saluran trasmisinya yang terbatas akan jarak. Antena televisi yang ada di pasaran sekarang ini sudah banyak jenisnya, Sejauh ini yang paling banyak beredar di pasaran yaitu antena televisi direksional yang kebanyakan terbuat dari bahan alumunium. Antena tersebut memfokuskan daya terimanya ke arah tertentu, sehingga jika kita mengarahkan ke satu arah, maka daya terimanya menjadi besar dan arah yang lain dayanya menjadi kecil, Ini disebabkan karena letak stasiun pemancar televisi yang letaknya sangat jauh, kemudian kondisi alam antara stasiun pemancar banyak gunung, Melihat fenomena tersebut di atas, pada tugas akhir ini akan dirancang sebuah antena pemancar televisi yang diharapkan memiliki gain yang cukup besar.
\end{abstract}

Kata Kunci: UHF, Ground Plane Antena, Televisi

\section{Pendahuluan}

Teknologi Informasi berkembang begitu pesat, waktu berganti diiringi perkembangan dan pembaruan teknologi yang baru, berbagai temuan baru, ide dan inovasi baru bermunculan. Televisi yang dahulu telah ditemukan hingga saat ini masih mempunyai peranan dan fungsi yang sama yaitu sebagai media penyebaran informasi dan sebagai sarana hiburan di seluruh kalangan masyarakat[1]. Tetapi televisi saja tidak cukup untuk melakukan peranannya, karena diperlukan suatu alat agar dapat memancarkan informasi tersebut lalu diterima dan ditampilkan pada televisi. Alat tersebut tiada lain yaitu antena pemancar[2].

Sejauh ini yang paling banyak beredar di pasaran yaitu antena televisi direksional yang kebanyakan terbuat dari bahan alumunium. Antena tersebut memfokuskan daya terimanya ke arah tertentu, sehingga jika kita mengarahkan ke satu arah, maka daya terimanya menjadi besar dan arah yang lain dayanya menjadi kecil, sedangkan beberapa stasiun televisi berbeda arah pancarnya sehingga jika kita mengarahkan antena tersebut ke satu sisi, maka di sisi yang lain kualitas gambar menjadi kurang baik, sehingga bila menginginkan siaran televisi yang lain, antena tersebut harus diputar arahnya[3][4].

Ini disebabkan karena letak stasiun pemancar televisi yang letaknya sangat jauh, kemudian

kondisi alam antara stasiun pemancar terdapat banyak gunung, dataran tinggi, sehingga sinyal yang di terima lemah dan daya yang dapat diterima oleh antena terbatas[5][6]. Untuk di kota besar mungkin ini jarang terjadi karena sinyal yang diterima antena biasanya kuat,

Melihat fenomena tersebut di atas, pada tugas akhir ini akan dirancang sebuah antena pemancar televisi yang diharapkan memiliki gain yang cukup besar, dan pola radiasi yang dapat di terima dari segala arah dalam satu bidang atau di sebut juga omnidireksional[7][8]. Kegunaan dari antena pemancar dengan polaradiasi ini agar para penerima tidak perlu melakukan perputaran arah antena.

\section{Metode penelitian}

Metode adalah sebuah cara atau rangkaian yang digunakan untuk menyelesaikan masalah. Metode yang digunakan dalam penelitian ini ada enam tahap. Metode pertama adalah penentuan variable penelitian.Variable dari penelitian ini adalah parameter yang digunakan sebagai indikator perbandingan. Tahap kedua adalah penentuan model yang digunakan yaitu dua metode yang akan dibandingkan[9][10]. Rancangan penelitian secara lengkap diuraikan 
pada tahap ketiga. Pada tahap keempat akan dibahas bagaimana teknik pengumpulan data dan teknik analisa pada tahap kelima.

Variabel penelitian yang digunakan pada penelitian ini adalah parameter yang ditentukan sebagai indikator perbandingan. Metode pengukuran nilai parameter-parameter ini[11][12]. Bandwidth suatu antena didefenisikan sebagai rentang frekuensi di mana kinerja antena yang berhubungan dengan beberapa karakteristik (seperti impedansi masukan, polarisasi, beamwidth, polarisasi, gain, efisiensi, VSWR, return loss) memenuhi spesifikasi standar. Bandwith dapat dicari dengan rumus.

Ada beberapa jenis bandwidth di antaranya :

a. Impedance bandwidth.

b. Pattern bandwidth

c. Polarization atau axial ratio bandwidth

Ada dua jenis penguatan (gain) pada antena, yaitu penguatan absolut (absolute gain) dan penguatan relatif (relative gain). Penguatan absolut pada sebuah antena didefenisikan sebagai perbandingan antara intensitas pada arah tertentu dengan intensitas radiasi yang diperoleh jika daya yang diterima oleh antena teradiasi secara isotropic[13][14]. Intensitas radiasi yang berhubungan dengan daya yang diradiasikan secara isotropic sama dengan daya yang diterima oleh antena (Pin) dibagi dengan $4 \pi$. Penguatan absolut ini dapat dihitung dengan rumus pada persamaan (2.8)[15][16].

VSWR adalah perbandingan antara amplitudo gelombang berdiri (standing wave) maksimum (|V|max) dengan minimum (|V|min). Pada saluran transmisi ada dua komponen gelombang tegangan, yaitu tegangan yang dikirimkan ( $\left.\mathrm{V} 0_{+}\right)$dan tegangan yang direfleksikan (V0-). Perbandingan antara tegangan yang direfleksikan dengan yang dikirimkan disebut sebagai koefisien refleksi tegangan $(\Gamma)$ dapat di cari dengan persamaan (2.3)[17][18].

Return Loss adalah cara lain mengungkapkan ketidakcocokan. Return Loss adalah rasio logaritmik yang diukur dalam $\mathrm{dB}$ yang membandingkan daya yang dipantulkan oleh antena dengan daya yang dimasukan ke dalam antena dari jalur pengiriman. Hubungan antara SWR dan Return Loss adalah dengan mengacu pada persamaan (2.7)[19][20].

Perancangan Proses pembuatan antena diawali dengan menentukan spesifikasi bentuk dan bahan antena beserta parameternya, yaitu frekuensi kerja, bandwidth, polarisasi, pola radiasi, return loss, dan gain[21][22]. Tabel 1 menunjukan spesifikasi antena yang digunakan dalam penelitian ini.

Tabel. 1 Spesifikasi Antena

\begin{tabular}{|l|l|}
\hline Spesifikasi & Keterangan \\
\hline Bahan Substrat & Pipa Alumunium \\
\hline Tebal Substrat & $1 \mathrm{~mm}$ \\
\hline Frekuensi Kerja & $442 \mathrm{MHz}$ \\
\hline Bandwidth & $4 \mathrm{MHz}$ \\
\hline Polaradiasi & Omnidirectional \\
\hline Polarisasi & Linear \\
\hline VSWR & $\leq 2$ \\
\hline Gain & $\geq 5 \mathrm{dBi}$ \\
\hline
\end{tabular}

Proses perancangan Variasi Antena Collinear Pada Pemancar Televisi Analog Dengan Frekuensi UHF $442 \mathrm{MHz}$ dilakukan secara bertahap. Dapat dilihat pada diagram alir dibawah ini yang dapat menjelaskan tentang proses pada Variasi Antena Collinear[23]. 


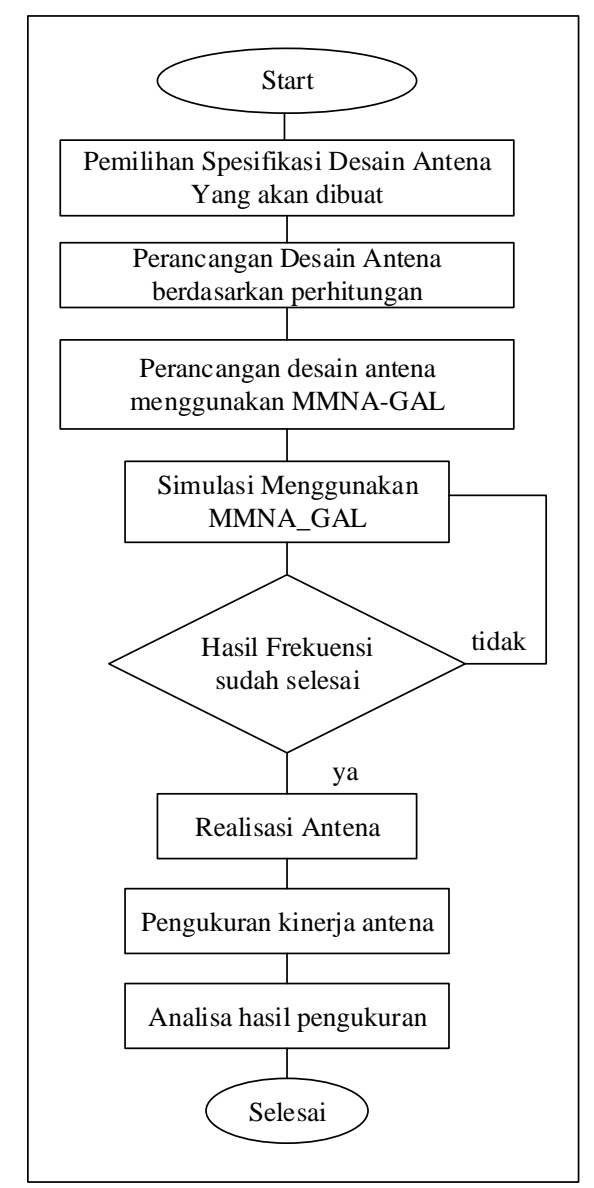

Gambar 3.1 Diagram alir perancangan Variasi Antena

Untuk dimensi minimum groundplane yang dibutuhkan oleh antenna mikrostrip diberikan melalui persamaan berikut.

$\mathrm{t}=$ ketebalan substat

$$
A g=6 t+a
$$

$\mathrm{a}=$ panjang saluran pencatu ditambah diameter dimensi patch.

Dengan asumsi awal tebal substrat $t=1.6 \mathrm{~mm}$, panjang saluran pencatu $34.205 \mathrm{~mm}$ dan diameter patch $29.4 \mathrm{~mm}$, akan diperoleh dimensi minimum groundplane Ag adalah sebesar $73.205 \mathrm{~mm}$. Dalam penelitian ini untuk memudahkan pada saat melakukan kalibrasi antena dimensi groundplane yang digunakan $100 \times 100 \mathrm{~mm}[24][25]$.

Simulasi antena Collinear dilakukan dengan menggunakan perangkat lunak MMNAGAL, hasil dari simulasi ini berupa pola antenna Collinear sesuai dimensi asli yang diinginkan. Pola yang telah terbentuk dari hasil simulasi ini yang nantinya akan dijadikan acuan dalam pembuatan antena Collinear. Simulasi pada perangkat lunak ini akan menghitung ulang parameter dimensi antena Collinear yang ada berdasarkan pada frekuensi kerja yang diinginkan[26].

Pengujian antena dilakukan di satu tempat, yaitu Universitas Merdeka Malang dengan menggunakan perangkat yang digunakan pada parabola dengan mengarahkan ke satelit Telkom 2 untuk memperoleh hasil yang diinginkan. Dan Lembaga Ilmu Pengetahuan Indonesia dengan menggunakan peralatan percobaan yang ada untuk mengukur VSWR, Gain dan RL antena.

Pengujian laboratorium dilakukan di Universitas Merdeka, Malang. Pengujian ini dilakukan pada dua antena Collinear yang telah dirancang, yaitu Collinear dengan tanpa modifikasi dan Collinear dengan modifikasi Ground Plane[27]. Pengujian ini dilakukan didalam ruangan. Dari hasil pengujian ini diperoleh data berupa Bandwidth, Gain, Return Loss dan VSWR antena yang telah dibuat. 
Rancangan penelitian ini menggunakan analisis kerja sistem. Dua antena yang telah ditentukan untuk disimulasikan sesuai dengan rancangan masing-masing. Hasil simulasi dibandingkan satu sama lain menggunakan parameter perbandingan yaitu Gain dan VSWR.

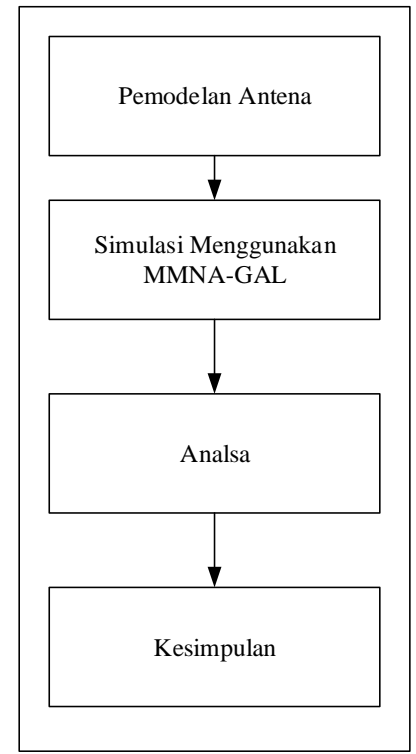

Gambar 3.2 Diagram Alir Rancangan Penelitian

\section{Hasil dan Analisis}

Data yang dihasilkan pada penelitian ini berupa hasil simulasi dari MMNA-GAL. Pengumpulan data dari kedua skema yang ditentukan akan dibandingkan sesuai dengan parameter perbandingan. Fungsi pada langkah ini terdiri atas pembuktian intregitas dari program dan melakukan evaluasi terhadap performansi dari jaringan yang disimulasikan.

Fungsi di atas mengacu pada pencapaian hasil akhir simulasi dengan mengumpulkan dan melakukan kompilasi terhadap keluaran hasil simulasi[28]. Visualisasi simulasi dapat diperoleh dengan melakukan pemrosesan terhadap Hasil kalkulasi dari MMNA-GAL. Pengolahan data dalam kalkulasi pada MMNA-GAL dapat menghasilkan sebuah nilai yang digunakan untuk menentukan parameter.

Penyimpulan hasil penelitian diperoleh dengan membandingkan kedua skema. Hasil dari setiap skema dapat digunakan sesuai dengan kondisi dan lingkungan. Kedua skema mempunyai karakteristik yang berbeda. Dari hasil simulasi tiap skema dapat kita manfaatkan untuk perbandingan mendapatkan hasil yang kita inginkan.

Setelah dilakukan perancangan Antena Collinear Dengan Frekuensi UHF $442 \mathrm{MHz}$ di simulator MMANA-GAL, tahap selanjutnya yang akan dilakukan adalah melakukan pengukuran dan analisis antena Antena Collinear dengan merubah ground plane menjadi 90 derajat. Sebelum antena Collinear ini diukur dan di analisis, antena Collinear terlebih dahulu harus memenuhi parameter antena pemancar pada frekuensi $442 \mathrm{MHz}$ pada saat disimulasikan. Adapun parameter antena yang digunakan untuk menentukan apakah antena Collinear sudah layak untuk dibuat adalah VSWR $\leq 2$ dan gain $\geq 5 \mathrm{dbi}$ dari antenna collinear ukuran standar sebagai bahan perbandingan. Apabila antena yang disimulasikan sudah mencapai nilai yang diharapkan, maka tahap selanjutnya adalah membangun antena tersebut dengan alumunium pipa berdiameter $1 \mathrm{~mm}, 9.5 \mathrm{~mm}, 13 \mathrm{~mm}, 16 \mathrm{~mm}, 22 \mathrm{~mm}$ untuk tiap-tiap elemen, konektor PL male, dan kabel penghubung dengan impedansi lima puluh ohm[29].

Berdasarkan rancangan yang telah dilakukan pada dan disimulasikan, maka dihasilkan sebuah grafik VSWR seperti pada Gambar 4.1. 


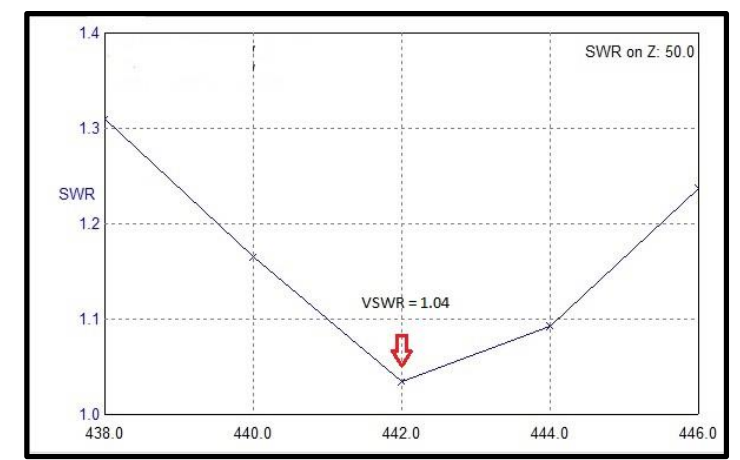

Gambar 4.1 Grafik VSWR Antena collinear standar

Gambar 4.1 adalah grafik VSWR yang diperoleh dari perancangan Antena collinear standar adalah 1.04. Berdasarkan dari hasil simulasi tersebut dapat diambil kesimpulan bahwa VSWR tersebut sudah sesuai dengan parameter yang diinginkan. Adapun tampilan yang menunjukkan nilai gain dan pola radiasi dari hasil perancangan awal dapat dilihat pada Gambar 4.2.

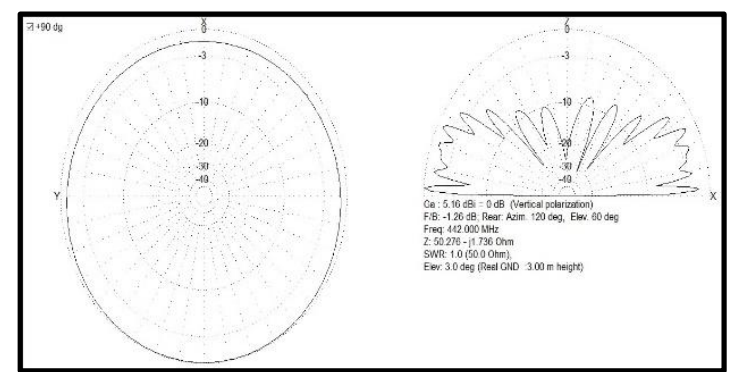

Gambar 4.2 Gain dan Pola Radiasi Hasil Simulasi Antena collinear standar

Berdasarkan dari Gambar 4.2, dapat diambil kesimpulan bahwa gain Antena collinear standar bernilai 5.16 dengan pola radiasi omnidirectional dimana nilai tersebut telah memenuhi parameter yang diinginkan[30].

Namun dapat ditingkatkan lagi dengan merubah sudut ground plane antenna menjadi 90 derajat, maka tahap selanjutnya yang akan dilakukan adalah karakterisasi Antena collinear.

Berdasarkan dari hasil simulasi dengan merubah sudut ground plane antena Collinear, dapat mencapai parameter yang diinginkan dengan gain $\geq 5 \mathrm{dbi}$ dengan VSWR $\leq 2$. Hasil simulasi optimasi perubahan sudut ground plane dapat dilihat pada Gambar 4.3 untuk grafik VSWR.

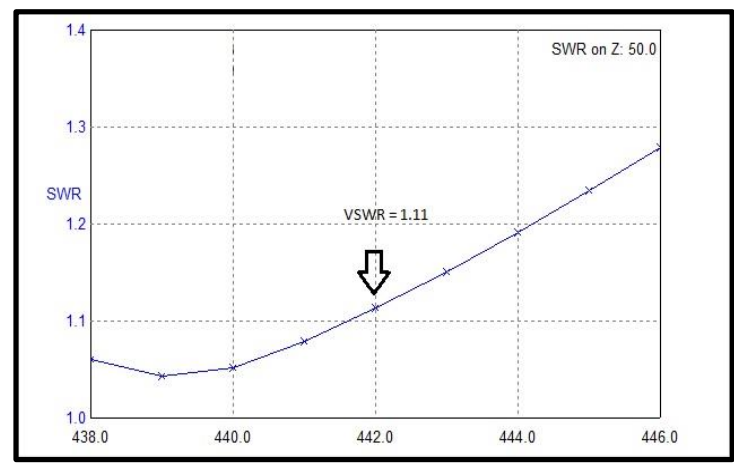

Gambar 4.3 Grafik VSWR Antena collinear modifikasi ground plane

Gambar 4.3 menunjukkan bahwa VSWR yang dihasilkan setelah dilakukan modifikasi dengan merubah sudut ground plane antenna menjadi 90 derajat diperoleh nilai sebesar 1.11. berdasarkan hasil tersebut, maka Antena collinear modifikasi ini dapat dilanjutkan ketahap membangun antena. Untuk memastikan apakah dengan merubah sudut ground plane antenna menjadi 90 derajat dapat dilanjutkan ketahap selanjutnya, maka hal yang harus diperhatikan 
lagi adalah nilai gain dan pola radiasi yang dihasilkan seperti yang diperlihatkan pada Gambar 4.4

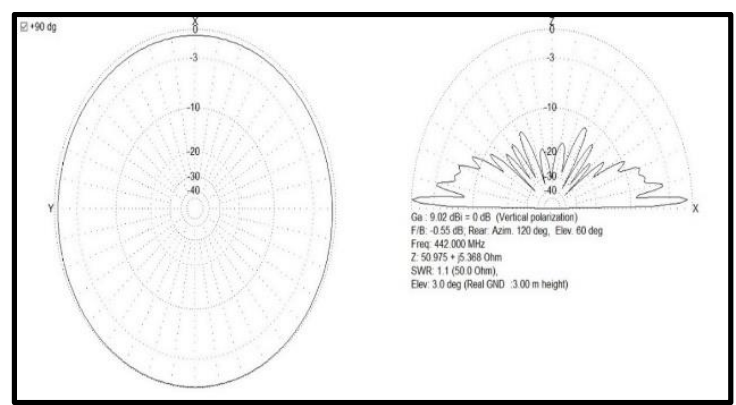

Gambar 4.4 Gain dan Pola Radiasi Hasil Simulasi Antena collinear modifikasi ground plane

Gambar 4.4 menunjukkan bahwa nilai gain yang dihasilkan setelah dilakukan perubahan sudut 90 derajat pada ground plane antena adalah sebesar $9.02 \mathrm{~dB}$ dengan pola radiasi omnidirectional. Berdasarkan dari hasil simulasi dan parameter yang ingin dicapai, ternyata dengan merubah sudut ground plane antenna menjadi 90 derajat dapat meningkatkan gain sebesar $3.86 \mathrm{~dB}$ dari desain antenna collinear dengan ground plane standar.

Pada bagian ini akan membahas tentang perbandingan simulasi dan pengukuran antena collinear standar dengan antena collinear termodifikasi. Perbandingan simulasi dan pengukuran antenna collinear standar dengan antena collinear termodifikasi dapat dilihat pada Tabel 4.1.

Tabel 4.1 Perbandingan Antena collinear standar dengan Antena Collinear termodifikasi

\begin{tabular}{|c|c|c|c|c|c|}
\hline Model antena & Frekuensi & Impedansi & Vswr & Gain & Polaradiasi \\
\hline Antena standar & $442 \mathrm{mhz}$ & $50.28 \mathrm{ohm}$ & 1.04 & $5.16 \mathrm{db}$ & Omnidirectional \\
\hline Antena termodifikasi & $442 \mathrm{mhz}$ & $53.97 \mathrm{ohm}$ & 1.11 & $9.02 \mathrm{db}$ & Omnidirectional \\
\hline
\end{tabular}

Dari hasil perbandingan Antena Collinear standar dengan Antena Collinear termodifikasi, nilai VSWR yang didapat pada saat simulasi antena Collinear standar dan antena Collinear adalah sebesar 1.04 dan 1.11 dengan gain sebesar 5.16 dbi dan 9.02 dbi. Berdasarkan hasil yang ditampilkan pada Tabel 4.1 dapat disimpulkan bahwa nilai gain antena meningkat setelah antenna collinear di modifikasi dengan melakukan perubahan sudut ground plane menjadi 90 derajat.

$$
\begin{gathered}
\text { Presentase Gain } \frac{\text { Gain antena Collinear Modifikasi }}{(\text { Gain Antena Colinear Modifikasi - Gain Antena Collinear standar })} \times 100 \% \\
\text { Presentase Gain } \frac{9.02}{(9.02-5.16)} \times 100 \%=2.34 \%
\end{gathered}
$$

Dimana selisih peningkatan gain antena Collinear dan Collinear setelah termodifikasi adalah sebesar $3.86 \mathrm{dbi}$. Hal ini dapat terjadi karena antena Collinear telah di modifikasi dengan merubah sudut ground plane menjadi 90 derajat.

Setelah didapat hasil simulasi yang optimal, tahap selanjutnya yang dilakukan adalah pengukuran. Nilai VSWR Collinear termodifikasi yang di dapat dari pengukuran adalah sebesar 1.07. Berdasarkan hasil pengukuran yang di dapat, dapat disimpulkan bahwa nilai VSWR pada saat pengukuran lebih baik daripada pada saat simulasi. Hal ini dapat terjadi karena bendabenda disekitar pengukuran antena dapat merubah VSWR atau karena simulator MMANA-GAL yang mempertimbangkan kemungkinan banyaknya gangguan yang akan terjadi.

\section{Simpulan}

Dari hasil yang diperoleh, maka dapat diambil kesimpulan sebagai berikut: 
a)Nilai VSWR antena Collinear modifikasi dengan merubah radial ground plane menjadi 90 derajat pada saat simulasi sebesar 1.11.

b)Nilai gain antena Collinear modifikasi dengan merubah radial ground plane menjadi 90 derajat pada saat simulasi sebesar $9.02 \mathrm{dbi}$.

c) Jika perancangan menggunakan rumus sesuai dengan teori, maka semakin besar ukuran fraktal nilai VSWR semakin mendekati $\leq 2$ tetapi nilai gain semakin kecil.

d)Jika perancangan menggunakan ukuran total panjang fraktal sama dengan setengah panjang elemen antena collinear, maka semakin kecil ukuran fraktal nilai VSWR yang didapat $\leq 2$ dan semakin besar gain yang diperoleh.

e)Dengan merubah radial ground plane menjadi 90 derajat dari ukuran antena Collinear biasa, antena Collinear yang dimodifikasi mempunyai kinerja yang lebih baik jika dibandingkan dengan antena Collinear biasa.

f) Hal yang harus diperhatikan pada saat perancangan antena Collinear adalah jenis elemen, ketebalan elemen, ukuran fraktal dan jarak antar elemen fraktal.

g)Hasil simulasi antena Collinear yang termodifikasi dengan merubah radial ground plane menjadi 90 derajat lebih baik daripada antena Collinear sebelum termodifikasi.

\section{References}

[1] C. A. Balanis, Modern antenna handbook. 2007.

[2] R. Yuwono, I. Mujahidin, A. Mustofa, and Aisah, "Rectifier using UFO microstrip antenna as electromagnetic energy harvester," Adv. Sci. Lett., 2015.

[3] H. J. Visser and R. J. M. Vullers, "RF energy harvesting and transport for wireless sensor network applications: Principles and requirements," Proceedings of the IEEE. 2013.

[4] M. T. Prakarsa, D. Wahyuni, N. Rachman, and I. Mujahidin, "Optimasi Sistem Komunikasi Dari Ht Dengan Hp Dalam Pelaksanaan Tugas Operasi TNI AD Menggunakan Metode DTMF," JASIEK (Jurnal Apl. Sains, Informasi, Elektron. dan Komputer), 2019.

[5] N. Liu et al., "Planar metamaterial analogue of electromagnetically induced transparency for plasmonic sensing," Nano Lett., 2010.

[6] I. Mujahidin and P. S. Arinda, "Antena Compact Double Square Marge 2, 6GHz Dengan Output Perbedaan Fase 90 Derajat Untuk Aplikasi LTE," JEECAE (Journal Electr. Electron. Control. Automot. Eng., vol. 4, no. 2, pp. 273-278, 2019.

[7] K. G. Ong, K. Zeng, and C. A. Grimes, "A wireless, passive carbon nanotube-based gas sensor," IEEE Sens. J., 2002.

[8] S. K. Sugiarto, I. Mujahidin, and A. B. Setiawan, "2, $5 \mathrm{GHz}$ Antena Mikrostrip Polarisasi Circular Model Patch Yin Yang untuk Wireless Sensor," JEECAE (Journal Electr. Electron. Control. Automot. Eng., vol. 4, no. 2, pp. 297-300, 2019.

[9] S. Laroche, "Polarimetric Doppler weather radar: principles and applications," Atmos. Res., 2002.

[10] I. Mujahidin, "Directional $1900 \mathrm{MHz}$ Square Patch Ring Slot Microstrip Antenna For WCDMA," JEEMECS (Journal Electr. Eng. Mechatron. Comput. Sci., 2019.

[11] I. Mujahidin, "VSWR (Voltage Standing Wave Ratio) dan Return loss," http://antenapropagasi.blogspot.com/2016/02/vswr-voltage-standing-wave-ratio-dan.html. 2018.

[12] I. Mujahidin and B. F. Hidayatulail, "2.4 GHz Square Ring Patch With Ring Slot Antenna For Self Injection Locked Radar," JEEMECS (Journal Electr. Eng. Mechatron. Comput. Sci., vol. 2, no. 2, 2019.

[13] D. M. Pozar, "New results for minimum Q, maximum gain, and polarization properties of electrically small arbitrary antennas," in 3rd European Conference on Antennas and Propagation, 2009.

[14] T. A. S, A. Rabi', D. Minggu, and I. Mujahidin, "Frequency Hopping Video Real Time Untuk Pengamanan Data Pengintaian Operasi Inteligence TNI," JASIEK (Jurnal Apl. Sains, Informasi, Elektron. dan Komputer), 2019.

[15] C. E. Balanis, "Antenna Theory: Analysis and Design, 3rd Edition - Constantine A. Balanis," Book. 2005.

[16] J. Lasmono, A. P. Sari, E. Kuncoro, and I. Mujahidin, "Optimasi Kerja Peluncur Roket Pada Robot Roda Rantai Untuk Menentukan Ketepatan Sudut Tembak," JASIEK (Jurnal Apl. Sains, Informasi, Elektron. dan Komputer), 2019.

[17] M. Chmiel et al., "LTE-Advanced," in LTE for UMTS: Evolution to LTE-Advanced: Second 
Edition, 2011.

[18] I. Mujahidin, "Desain Matematis Antena Mikrostrip," http://antenapropagasi.blogspot.com/2016/02/desain-matematis-antenamikrostrip_17.html. 2018.

[19] B. F. Hidayatulail and I. Mujahidin, "Potential OF 77, $78 \mathrm{~mW}$ Red Diode Laser For Photodynamic," JEEMECS (Journal Electr. Eng. Mechatron. Comput. Sci., vol. 2, no. 2, 2019.

[20] I. Mujahidin, "Parameter Antena," http://antenapropagasi.blogspot.com/2016/02/parameterantena.html. 2018.

[21] A. Ghosh, R. Ratasuk, B. Mondal, N. Mangalvedhe, and T. Thomas, "LTE-advanced: Nextgeneration wireless broadband technology," IEEE Wirel. Commun., 2010.

[22] I. Mujahidin, S. H. Pramono, and A. Muslim, "5.5 Ghz Directional Antenna with 90 Degree Phase Difference Output," 2018.

[23] I. Mujahidin, R. Yuwono, and A. Mustofa, "Rancang Bangun Rectifier Antenna Mikrostrip Ufo Pada Frekuensi Ultra Wideband (UWB) Sebagai Pemanen Energi Elektromagnetik," J. Mhs. TEUB, vol. 3, no. 2, 2015.

[24] A. Gllsson, "Microstrip Antenna Design Handbook," IEEEAnfannas and Propagation Magazine, 2003.

[25] S. H. Anwariningsih, "Perhitungan Luas Dan Keliling Bangun Geometri Menggunakan Pendekatan Morfologi," Semin. Nas. Apl. Teknol. Inf. 2009 - ISSN1907-5022, 2009.

[26] D. Fang, Antenna Theory and Microstrip Antennas. 2011.

[27] E. M. Cheng et al., "Development of microstrip patch antenna sensing system for salinity and sugar detection in water," Int. J. Mech. Mechatronics Eng., 2014.

[28] G. F. Pedersen, M. Tartiere, and M. B. Knudsen, "Radiation efficiency of handheld phones," 2002.

[29] I. "Langkah Mujahidin, Desain Antena," http://antenapropagasi.blogspot.com/2016/02/langkah-desain-antena.html. 2018.

[30] Z. W. Sim, R. Shuttleworth, and B. Grieve, "Investigation of PCB microstrip patch receiving antenna for outdoor RF energy harvesting in wireless sensor networks," in Loughborough Antennas and Propagation Conference, LAPC 2009 - Conference Proceedings, 2009. 